\title{
Disiplin Kerja, Pengalaman Kerja Terhadap Kepuasan dan Kinerja Pengawas
}

\author{
Sabirin $^{1}$, Ilham $^{2}$ \\ ${ }^{1}$ Pascasarjana Program Doktor Ilmu Manajemen, Universitas Muslim Indonesia \\ Jl. Urip Sumoharjo N0. 225 Makassar, Indonesia \\ Email: sabirin.wawo69@gmail.com \\ ${ }^{2}$ Fakultas Ekonomi dan Bisnis, Universitas Lakidende Unaaha \\ Jl. Sultan Hasanuddin, No. 234, Wawotobi, Lalosabila, Unaaha, \\ Kabupaten Konawe, Sulawesi Tenggara, Indonesia \\ Koresponden:ilham@unilaki.ac.id
}

\footnotetext{
Artikel Info

Received:

14 Februari 2020

Revised:

28 September 2020

Accepted:

30 Oktober 2020
}

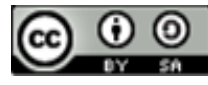

Published by Jurnal Ilmiah

Manajemen dan Bisnis, Indonesia | Copyright (C) 2020 by the Author(s) | This is an open access article distributed under the

Creative Commons Attribution License

http://creativecommons.org/licenses /by/4.0), which permitsunrestricted use

distribution, and reproduction in any medium, provided the original work is properly cited.

\begin{abstract}
ABSTRAK
Penelitian ini bertujuan untuk mengetahui pengaruh langsung dan tidak langsung disiplin kerja dan pengalaman kerja terhadap kepuasan kerja dan kinerja pengawas pada dinas Pendidikan Provinsi Sulawesi Selatan. penelitian yang digunakan adalah explanatif dengan pendekatan survey. Teknik pengambilan sampel dengan metode simple random sampling. Metode yang digunakan dalam penelitian ini adalah dengan menggunakan metode Partial Least Square (PLS). Dari hasil penelitian terhadap pengaruh langsung menunjukkan disiplin kerja tidak memberikan pengaruh terhadap kepuasan kerja, disiplin kerja berpengaruh positif dan signifikan terhadap kinerja, pengalamn kerja berpengaruh positif dan signifikan terhadap kepuasan kerja, pengalaman kerja tidak berpengaruh secara langsung terhadap kinerja, selanjutnya pengaruh disiplin kerja berpengaruh negatif dan signifikan terhadap kinerja melalui kepuasan kerja, serta pengalaman kerja berpengaruh positif dan signifikan terhadap kinerja melalui kepuasan kerja.
\end{abstract}

Kata Kunci: Disiplin Kerja, Pengalamn Kerja, Kepuasan Kerja dan Kinerja Pengawas

\section{Effect of Work Discipline, Work Experience on Supervisor Satisfaction and Performance}

This research aims to determine the direct and indirect influence of work discipline and work experience on job satisfaction and supervisor performance in the Education office of South Sulawesi Province. The research used is explanative with survey approach Sampling technique with simple random sampling method. The method used in this study is to use the Partial Least Square (PLS) method. From the results of the study to the direct influence shows work discipline does not affect job satisfaction, work discipline has a positive and significant effect on performance, work experience has a positive and significant effect on job satisfaction, work experience has no direct effect on performance, further influence of work discipline negatively and significantly affects performance through job satisfaction, and work experience has a positive and significant effect on performance through job satisfaction.

Keywords : work discipline, work in, job satisfaction and performance supervisor.

DOI: $h$ https://doi.org/10.30596/jimb.v21i2.4295

JEL CLASSIFICATION: O, O1, 015

Cara Sitasi :

Sabirin., Ilham. (2020). Disiplin Kerja, Pengalaman Kerja Terhadap Kepuasan dan Kinerja Pengawas. Jurnal Ilmiah Manajemen dan Bisnis, 21(2), 123-135. https://doi.org/10.30596/jimb.v21i2.4295. 


\section{PENDAHULUAN}

Era revolusi industry 4.0 memberikan pengaruh yang kuat terhadap manajemen sumber daya manusia dan telah menimbulkan kompleksitas masalah. Tantangan tersebut harus dihadapi dengan melakukan perubahan paradigma dan perbaikan manajemen pada setiap organisasi. Salah satu langkah perubahan paradigma tersebut dengan menempatkan sumber daya manusia (SDM) sebagai prioritas.

Pegawai merupakan sumberdaya yang penting bagi organisasi, karena memiliki bakat, tenaga dan kreativitas yang sangat di butuhkan oleh organisasi untuk mencapai tujuannya, kinerja suatu organisasi tidak terlepas dari kinerja individu dan para anggotanya, apabila kinerja individu membaik maka secara langsung maupun tidak langsung akan berpengaruh terhadap kinerja organisasi. Keberhasilan suatu organisasi dipengaruhi oleh kinerja pegawai dalam melaksanakan tugas sesuai dengan tanggung jawab yang diberikan kepadanya. Pegawai dengan kinerja yang baik akan membawa kemajuan dalam organisasi yang lebih baik, sehingga dapat berkembangnya jiwa profesionalisme kerja yaitu dengan cara peningkatan kapasitas sumber daya manusia dalam hal ini peningkatan pengalaman kerja dan peningkatan disiplin kerja.

Menurut (Hutagalung \& Triastuti, 2019) bahwa kinerja pegawai dapat diketahui hanya jika individu atau kelompok individu tersebut memiliki kriteria keberhasilan yang telah ditetapkan. Kriteria keberhasilan ini berupa tujuan-tujuan atau target-target tertentu yang hendak dicapai.

Menurut (Nugrohadi et al., 2019), menjelaskan bahwa disiplin kerja merupakan kesadaran dan kesediaan seseorang untuk mematuhi semua aturan organisasi dan norma sosial yang berlaku. Selanjutnya (Muntazeri et al., 2018) menyatakan bahwa pengalaman kerja merupakan tingkat penguasaan pengetahuan dan keterampilan seseorang yang dapat diukur dari masa hidup seseorang. Selain itu, (Itafia et al., 2014) mengatakan bahwa pengalaman merupakan pengetahuan atau keterampilan yang dikenal dan dikendalikan oleh seseorang pegawai sebagai akibat perbuatan atau pekerjaan yang telah dilakukan sebelum untuk jangka waktu tertentu.

Hasil penelitian yang menyatakan bahwa disiplin kerja berpengaruh tehadap kinerja pegawai jika semakin baik pegawai menerapkan disiplin kerja mereka dan mematuhi peraturan/regulasi organisasi, akan meningkatkan kinerja pegawai (Sudiardhita et al., 2018), (Agussalim, 2017), hal senada juga dioleh (Muntazeri et al., 2018) bahwa dengan peningkatan disiplin kerja akan diikutipula peningkatan kepuasan kerja pegawai, temuan ini diperkuat oleh temuan (Nugrohadi et al., 2019), (Yuliandi \& Tahir, 2019) dan (Barasa et al., 2018).

Faktor disiplin kerja dan pengalaman kerja dapat mempengaruhi tingkat kepuasan kerja maupun kinerja para pegawai baik secara langsung maupun secara tidak langsung, hasil penelitian (Anggun Tri Indriastuti, 2014) yang mendefinisikan kepuasan kerja sebagai perasaan positif pada suatu pekerjaan, yang merupakan dampak atau hasil evaluasi dari berbagai aspek pekerjaan itu sendiri, temuan ini diperkuat oleh hasil penelitian (Gesinde \& Adejumo, 2012) bahwa pengalaman kerja memiliki hubungan positif terhadap kepuasan kerja. Selanjutnya (Muntazeri et al., 2018) dan (Sudiardhita et al., 2018) menyimpulkan bahwa pengalaman kerja memiliki pengaruh pada kepuasan, Hal lain juga disampaikan oleh (Sudiardhita et al., 2018) bahwa kepuasan kerja yang dimiliki seorang pegawai maka akan dampak terhadap kinerja pegawai yang diperkuat oleh temuan (Barasa et al., 2018).

Pengawas pada Dinas Pendidikan Provinsi Sulawesi Selatan memiliki peran yang sangat crucial dalam mata rantai peningkatan mutu pendidikan di Indonesia dan di Sulawesi Selatan khususnya dimana pengawas sebagai ujung tombak dalam meningkatkan mutu pendidikan harus lebih dahulu meningkatkan disiplin kerja dan kompetensi dengan memiliki pengalaman kerja yang baik. Hasil observasi yang telah dilakukan ditemukan beberapa masalah yaitu (1) beberapa pegawai masih kurang bertanggung jawab terhadap tugas dan tanggung jawab yang di amanahkan kepadanya. Seperti masih adanya pegawai yang menyampaikan laporan hasil 
pengawasan melewati waktu yang telah ditetapkan bahkan terkadang laporan bulanan disampaikan setiap bulan tetapi disampaikan dua bulan berikutnya (2) kinerja pegawai masih belum sesuai dengan harapan lembaga. Misalnya pegawai belum mampu memenuhi target selesainya tugas yang deadline, dan perlunya waktu cukup lama ketika menyelesaikan tugas dan tanggungjawab yang diberikan.

\section{METODE}

Penelitian ini bertujuan untuk mendapatkan bukti empiris dan mengembangkan teori, yaitu pengaruh antara disiplin kerja dan pengalaman kerja terhadap kepuasan kerja dan kinerja pegawai pada kantor Pengawas Disdik Provinsi Sulawesi Selatan. Melihat permasalahan dan tujuan penelitian yang hendak dicapai maka penelitian ini menggunakan pendekatan penelitian Explanatif dengan pendekatan survey. Adapun operasionalisasi variabel penelitian untuk variabel Disiplin Kerja terdiri dari empat indikator (Sutrisno, 2009), variabel Pengalaman Kerja terdiri dari lima indikator (Handoko, 2001), variabel Kepuasan Kerja terdiri dari lima indikator (Smith, Kendall \& Hulin dalam (Luthans et al., 2006) dan variabel Kinerja terdiri dari lima indikator (Robbins, S. P., \& Judge, 2006). Populasi dalam penelitian ini adalah Pengawas pada Dinas Pendidikan (Disdik) Provinsi Sulawesi Selatan, berjumlah 200 orang pegawai. Indikator dalam penelitian ini sebanyak 19 indikator, maka ukuran sampel minimal 5 x 19 atau sebesar 95 sampel. (Solimun, 2002). Teknik pengambilan sampel digunakan teknik simple random sampling, yaitu pengambilan sampel dimana tiap unsur yang membentuk populasi diberi kesempatan yang sama untuk terpilih menjadi sampel.(Sugiyono, 2017). Dalam penelitian ini analisis data menggunakan pendekatan Partial Least Square (PLS). PLS adalah model persamaan Structural Equation Modeling (SEM) yang berbasis komponen atau varian. Menurut (Imam Ghozali, 2006), PLS merupakan pendekatan alternative yang bergeser dari pendekatan SEM berbasis kovarian menjadi berbasis varian. SEM yang berbasis kovarian umumnya menguji kausalitas/teori sedangkan PLS lebih bersifat predictive model. PLS merupakan metode analisis yang powerfull (Imam Ghozali, 2006), karena tidak didasarkan pada banyak asumsi terdistribusi normal, sampel tidak harus besar.

\section{HASIL DAN PEMBAHASAN \\ Evaluasi Outer Model}

Model pengukuran atau Outer Model dengan indikator reflektif dievaluasi dengan convergent dan discriminant validity dari indikatornya dan composite reliability untuk blok indikator Chin dalam (Imam, 2011). Model awal dari penelitian ini adalah sebagai berikut konstruk disiplin kerja (X1) diukur dengan 4 indikator reflektif, pengalaman kerja (X2) dengan 5 indikator reflektif, kepuasan kerja (Y1) diukur dengan 5 indikator reflektif dan kinerja diukur dengan 5 indikator reflektif.

Untuk menguji convergent validity digunakan nilai outer loading atau loading factor. Suatu indikator dinyatakan memenuhi convergent validity dalam kategori baik apabila nilai outer loading $>0,7$. Berikut adalah nilai outer loading dari masing-masing indikator pada variabel penelitian, dapat dilihat pada tabel 1 . 
Tabel 1. Outer Loadings

\begin{tabular}{ccccc}
\hline Indikator & $\begin{array}{c}\text { Disiplin Kerja (X1) } \\
\text { X1.1 }\end{array}$ Pengalaman Kerja & $\begin{array}{c}\text { Kepuasan Kerja } \\
\text { (X2) }\end{array}$ & $\begin{array}{c}\text { Kinerja Pengawas } \\
\text { (Y2) }\end{array}$ \\
\hline X1.2 & 0,560191 & & & \\
X1.3 & 0,808543 & & & \\
X1.4 & 0,866860 & & & \\
X2.1 & 0,716703 & & & \\
X2.2 & & 0,633893 & & \\
X2.3 & & 0,881141 & & \\
X2.4 & & 0,893538 & & \\
X2.5 & & 0,666312 & & \\
Y1.1 & & 0,605823 & & \\
Y1.2 & & & 0,860869 & \\
Y1.3 & & & 0,597084 & \\
Y1.4 & & & 0,707761 & \\
Y1.5 & & & 0,714037 & \\
Y2.1 & & & 0,647105 & \\
Y2.2 & & & & 0,668306 \\
Y2.3 & & & & 0,732977 \\
Y2.4 & & & & 0,910975 \\
Y2.5 & & & 0,623130 \\
\hline
\end{tabular}

Tabel 1, diketahui bahwa masing-masing indikator variabel penelitian banyak yang memiliki nilai outer loading $>0,7$. Namun, terlihat masih terdapat beberapa indikator yang memiliki nilai outer loading < 0,7. (Imam Ghozali, 2006), nilai outer loading antara 0,5-0,6 sudah dianggap cukup untuk memenuhi syarat convergent validity, tidak ada indikator variabel yang nilai outer loading-nya di bawah 0,5 , sehingga semua indikator dinyatakan layak atau valid untuk digunakan penelitian dan dapat digunakan untuk analisis lebih lanjut, hal ini berarti seluruh indikator valid dalam mengukur konstruknya masing-masing, dengan demikian dalam tahap ini tidak ada indikator yang didrop dari model.

\section{Convergent Validity}

Ukuran reflektif individual dikatakan tinggi jika berkorelasi lebih dari 0,70 dengan construct yang ingin diukur. Namun demikian untuk penelitian tahap awal dari pengembangan skala pengukuran nilai loading 0,50 sampai 0,60 dianggap cukup (Imam Ghozali, 2006).

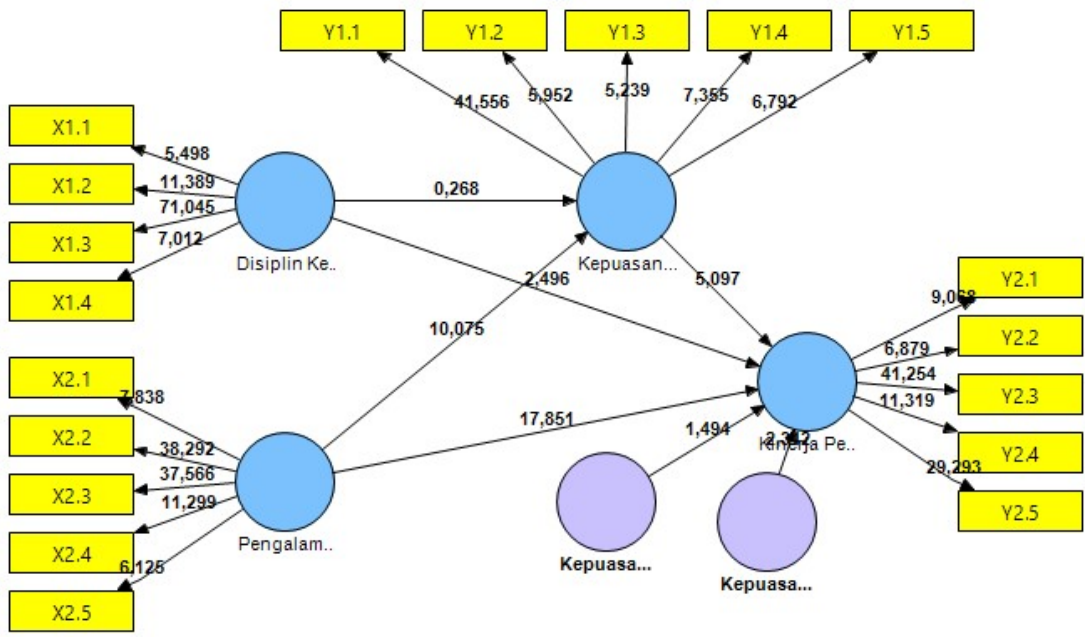

Gambar 1. Convergent Validity 
Berdasarkan pada model pengukuran Gambar 2, seluruh indikator yaitu analisis pada variabel penelitian dengan loading factor lebih besar dari 0,50 sehingga dinyatakan signifikan atau memenuhi syarat convergent validity.

\section{Average Variance Extracted (AVE) dan Corelation Laten}

Metode lain untuk menilai discriminat validity adalah membandingkan nilai square root of average variance extracted (AVE) setiap konstruk dengan korelasi antar konstruk dengan konstruk lainnya dalam model. Jika nila akar kuadrat AVE setiap konstruk lebih besar dari pada nilai korelasi antar konstruk dengan konstruk lainnya dalam model, maka dikatakan memiliki nilai discriminat validity yang baik Forwell dan Lacker, dalam (Imam, 2011). Hasil pengujian AVE dapat dilihat pada Tabel 2 dibawah ini

Tabel 2. Pengujian AVE

\begin{tabular}{lc}
\hline \multicolumn{1}{c}{ Variabel } & AVE \\
\hline Disiplin Kerja (X1) & 0,571394 \\
Kepuasan Kerja (Y1) & 0,545425 \\
Kepuasan Kerja (Y1)* Disiplin Kerja (X1) & 0,598457 \\
Kepuasan Kerja (Y1)* Pengalaman Kerja (X2) & 0,580811 \\
Kinerja Pengawas (Y2) & 0,593458 \\
Pengalaman Kerja (X2) & 0,557527 \\
\hline
\end{tabular}

Nilai AVE pada tabel 2 menunjukkan semua variabel nilainya $>0,50$ sehingga dapat dikatakan bahwa tiap indikator yang telah diukur telah dapat merefleksikan variabelnya masingmasing secara valid.

\section{Cronbach's Alpha dan Composite Reliability}

Pemeriksaan selanjutnya dari convergent calidity adalah reliability konstruk dengan melihat output composite reliability atau cronbach's Alpha. Kriteria dikatakan reliabel adalah nilai composite reliability atau cronbach's Alpha lebih dari 0,70 (Yamin dan Heri Kurniawan dalam (Imam, 2011).

Tabel 3. Cronbach's Alpha dan Composite Reliability

\begin{tabular}{lcc}
\hline \multicolumn{1}{c}{ Variabel } & Composite Reliability & Cronbachs Alpha \\
\hline Disiplin Kerja (X1) & 0,838392 & 0,749221 \\
Kepuasan Kerja (Y1) & 0,834164 & 0,753331 \\
Kepuasan Kerja (Y1)* Disiplin Kerja (X1) & 0,964475 & 0,956613 \\
Kepuasan Kerja (Y1)* Pengalaman Kerja (X2) & 0,969640 & 0,964708 \\
Kinerja Pengawas (Y2) & 0,877178 & 0,821830 \\
Pengalaman Kerja (X2) & 0,859621 & 0,793810 \\
\hline
\end{tabular}

\section{Evaluasi Inner Model dan Outer Loading}

Inner model adalah pengujian dengan cara mengevaluasi antar konstruk laten yang telah dihipotesikan dalam penelitian. Bootstrapping adalah prosedur atau teknik statistic resampling. Resampling berarti bahwa responden ditarik secara random dengan replacement, dari sampel original berkali-kali hingga diperoleh observasi (Ghazali \& Latan, 2012). 


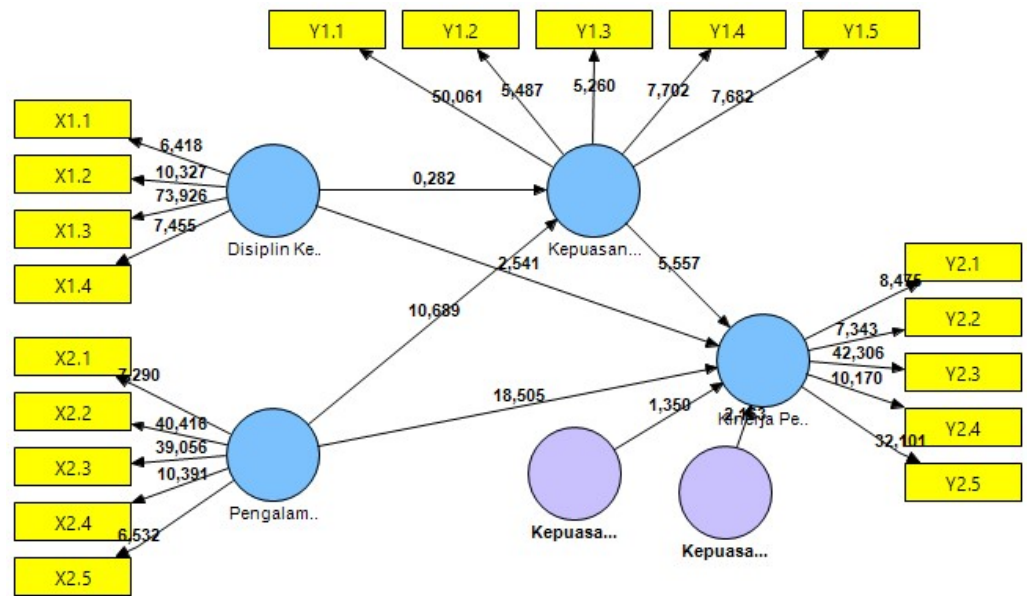

Gambar 2. Evaluasi Inner Model

Berdasarkan Gambar 2, dapat teerlihat juga bahwa semua jalur sudah memenuhi angka signifikan pada CI 95\% > $(1,96)$. Hal ini menjadi persyaratan pada evaluasi dengan loading factor yaitu dilakukan untuk menilai signifikansi konstruk laten dengan kosntruknya.

Tabel 4. Boostraping

\begin{tabular}{lccccc}
\hline \multicolumn{1}{c}{ Variabel } & $\begin{array}{c}\text { Original } \\
\text { Sample (O) }\end{array}$ & $\begin{array}{c}\text { Sample } \\
\text { Mean (M) }\end{array}$ & $\begin{array}{c}\text { Standard } \\
\text { Deviation } \\
\text { (STDEV) }\end{array}$ & $\begin{array}{c}\text { Standard } \\
\text { Error } \\
\text { (STERR) }\end{array}$ & $\begin{array}{c}\text { T Statistics } \\
\text { (|O/STERR|) }\end{array}$ \\
\hline $\begin{array}{l}\text { Disiplin Kerja (X1) -> Kepuasan Kerja } \\
\text { (Y1) }\end{array}$ & 0,026173 & 0,050414 & 0,102186 & 0,102186 & 0,256128 \\
$\begin{array}{l}\text { Disiplin Kerja (X1) -> Kinerja Pengawas } \\
\text { (Y2) }\end{array}$ & 0,128592 & 0,124744 & 0,050713 & 0,050713 & 2,535693 \\
$\begin{array}{l}\text { Kepuasan Kerja (Y1) -> Kinerja } \\
\text { Pengawas (Y2) }\end{array}$ & 0,312501 & 0,308232 & 0,062181 & 0,062181 & 5,025659 \\
$\begin{array}{l}\text { Kepuasan Kerja (Y1) * Disiplin Kerja (X1) } \\
\text {-> Kinerja Pengawas (Y2) }\end{array}$ & 0,158193 & 0,151787 & 0,067453 & 0,067453 & 2,345233 \\
$\begin{array}{l}\text { Kepuasan Kerja (Y1) * Pengalaman Kerja } \\
\text { (X2) -> Kinerja Pengawas (Y2) }\end{array}$ & 0,088652 & 0,086137 & 0,059792 & 0,059792 & 5,482682 \\
$\begin{array}{l}\text { Pengalaman Kerja (X2) -> Kepuasan } \\
\text { Kerja (Y1) }\end{array}$ & 0,898353 & 0,880636 & 0,091603 & 0,091603 & 9,806999 \\
$\begin{array}{l}\text { Pengalaman Kerja (X2) -> Kinerja } \\
\text { Pengawas (Y2) }\end{array}$ & 1,098066 & 1,101931 & 0,065965 & 0,065965 & 16,646102 \\
\hline
\end{tabular}

Berdasarkan model awal, maka dapat dikatakan bahwa hubungan antara variable laten dengan lainnya bila menunjukkan angka di atas 1,96 dengan parameter estimasi 95\% dinyatakan valid. Selanjutnya dilihat seberapa besar kekuatan variabel eksogen dan variabel endogen yang bersifat dependen pada model awal ini dengan cara melihat besarnya nilai $\mathrm{R}$ Square pada masing-masing variabel endogen tersebut pada tabel 5 dibawah ini: 
Tabel 5. R Square

\begin{tabular}{lc}
\hline \multicolumn{1}{c}{ Variabel } & R Square \\
\hline Disiplin Kerja (X1) & 0,846940 \\
Kepuasan Kerja (Y1) & \\
Kepuasan Kerja (Y1) * Disiplin Kerja (X1) & \\
Kepuasan Kerja (Y1) * Pengalaman Kerja (X2) & \\
Kinerja Pengawas (Y2) & 0,958002 \\
Pengalaman Kerja (X2) & \\
\hline
\end{tabular}

Tabel 5, menjelaskan sumbangan dari variabel yang mempengaruhi variable yang ada di tabel R-Square, nilai R-Square variabel kepuasan kerja sebesar 0,846 atau $84 \%$ artinya sebesar $16 \%$ dipengaruhi oleh faktor-faktor lain diluar penelitian ini. Sedangkan variabel kinerja pegawai sebesar 0,958 atau $95 \%$. Hal ini berarti $5 \%$ dipengaruhi oleh faktor-faktor lain diluar penelitian ini. Sebelum menguji Hipotesis penelitian salah satu pengujian yang juga perlu dilakukan adalah predictive relavance (Nilai Q Square) yang berfungsi untuk menilai besaran keragaman atau variasi data penelitian terhadap fenomena yang sedang dikaji dan juga juga estimasi parameternya.

\section{Pengujian Hipotesis Penelitian}

Untuk mengetahui keajegan model yang diusulkan pada suatu populasi dilihat nilai hubungan antara satu variabel dengan variabel lainnya atau nilai koefisien path (rho) nya dengan cara melihat besarnya nilai $O$ (original sample) serta nilai $T$ statistiknya sebagai suatu pernyataan nilai tingkat signifikansi hubungan antara satu variabel dengan variabel lainnya (tingkat signifikansi diambil pada level kesalahan 5\% atau berada pada $T$ diatas 1,96).

Tabel 6. Pengujian Hipotesis

\begin{tabular}{|c|c|c|c|c|}
\hline Hipotesis & Variabel & $\begin{array}{l}\text { Original Sample } \\
\text { (O) }\end{array}$ & $\begin{array}{l}\text { T Statistics } \\
\text { (|O/STERR|) }\end{array}$ & Signifikasi \\
\hline $\mathrm{H} 1$ & $\begin{array}{l}\text { Disiplin Kerja (X1) -> Kepuasan Kerja } \\
\text { (Y1) }\end{array}$ & 0,026173 & 0,256128 & $\begin{array}{l}\text { Tidak Ada Pengaruh } \\
\text { Yang Signifikan }\end{array}$ \\
\hline $\mathrm{H} 2$ & $\begin{array}{l}\text { Disiplin Kerja (X1) -> Kinerja } \\
\text { Pengawas (Y2) }\end{array}$ & 0,128592 & 2,535693 & $\begin{array}{l}\text { Ada Pengaruh Signifikan } \\
\text { dan Bernilai Positif }\end{array}$ \\
\hline $\mathrm{H} 3$ & $\begin{array}{l}\text { Kepuasan Kerja (Y1) -> Kinerja } \\
\text { Pengawas (Y2) }\end{array}$ & 0,312501 & 5,025659 & $\begin{array}{l}\text { Ada Pengaruh Signifikan } \\
\text { dan Bernilai Positif }\end{array}$ \\
\hline $\mathrm{H} 4$ & $\begin{array}{l}\text { Kepuasan Kerja }(\mathrm{Y} 1){ }^{*} \text { Disiplin Kerja } \\
(\mathrm{X} 1)->\text { Kinerja Pengawas }(\mathrm{Y} 2)\end{array}$ & 0,158193 & 2,345233 & $\begin{array}{l}\text { Ada Pengaruh Signifikan } \\
\text { dan Bernilai Positif }\end{array}$ \\
\hline $\mathrm{H} 5$ & $\begin{array}{l}\text { Kepuasan Kerja }(\mathrm{Y} 1){ }^{*} \text { Pengalaman } \\
\text { Kerja }(\mathrm{X} 2) \text {-> Kinerja Pengawas }(\mathrm{Y} 2)\end{array}$ & 0,088652 & 5,482682 & $\begin{array}{l}\text { Ada Pengaruh Signifikan } \\
\text { dan Bernilai Positif }\end{array}$ \\
\hline $\mathrm{H} 6$ & $\begin{array}{l}\text { Pengalaman Kerja (X2) -> Kepuasan } \\
\text { Kerja (Y1) }\end{array}$ & 0,898353 & 9,806999 & $\begin{array}{l}\text { Ada Pengaruh Signifikan } \\
\text { dan Bernilai Negatif }\end{array}$ \\
\hline $\mathrm{H} 7$ & $\begin{array}{l}\text { Pengalaman Kerja (X2) -> Kinerja } \\
\text { Pengawas (Y2) }\end{array}$ & 1,098066 & 16,646102 & $\begin{array}{l}\text { Ada Pengaruh Signifikan } \\
\text { dan Bernilai Positif }\end{array}$ \\
\hline
\end{tabular}


Hasil uji R-Square diperoleh nilai R-Square variabel kepuasan kerja sebesar 0,846 atau $84 \%$ artinya sebesar $16 \%$ dipengaruhi oleh faktor-faktor lain diluar penelitian ini. Sedangkan variabel kinerja pegawai sebesar 0,956 atau $95 \%$. Hal ini berarti 4\% dipengaruhi oleh faktor-faktor lain diluar penelitian ini.

1. Disiplin kerja tidak berpengaruh positif dan signifikan terhadap kepuasan kerja pengawas. Hasil penelitian menemukan bahwa disiplin kerja tidak terbukti memberikan pengaruh yang signifikan terhadap kepuasan kerja pengawas. T-statistik menunjukkan nilai $0.256<1,96$.

2. Disiplin kerja berpengaruh positif dan signifikan terhadap kinerja pegawai, Hal ini terbukti dengan nilai T-statistik menunjukkan nilai $2.535>1,96$.

3. Kepuasan kerja berpengaruh positif dan signifikan terhadap kinerja pengawas. Hasil uji menunjukkan nilai T-Statistics sebesar 5.025.

4. Disiplin kerja berpengaruh positif dan signifikan terhadap kinerja pengawas melalui kepuasan kerja, ini terbukti dengan nilai T-statistik $2.345>1,96$.

5. Penglaman kerja berpengaruh positif dan signifikan terhadap kinerja pengawas melalui kepuasan kerja, ini terbukti dengan nilai T-statistik $5.482>1,96$, sehingga disimpulkan hipotesis 5 diterima.

6. Penglaman kerja berpengaruh positif dan signifikan terhadap kepuasan kerja. Dapat dilihat hasil uji nilai T-statistik menunjukkan nilai 9.806 $>1,96$.

7. Pengalaman kerja berpengaruh positif dan signifikan terhadap kinerja pengawas, terbukti nilai T-statistik sebesar $16.646<1,96$.

\section{Pembahasan}

\section{Pengaruh Disiplin Kerja Terhadap Kepuasan Kerja Pengawas}

Berdasarkan hasil penelitian diatas bahwa tidak ada pengaruh yang signifikan antara disiplin terhadap kepuasan kerja, disebabkan oleh adanya sikap disiplin yang rendah, sehingga harus ditanamkan dan dibudayakan oleh setiap pengawas agar dapat memiliki sikap displin pada dirinya untuk mendukung tercapainya tujuan organisasi. Hasil penelitian ini pada dasamya tidak sesuai dengan hasil penelitian yang dikemukakan oleh oleh (Agussalim, 2017), (Nugrohadi et al., 2019) dan (Gesinde \& Adejumo, 2012), yang menyimpulkan bahwa disiplin kerja berpengaruh signifikan terhadap kepuasan pegawai, dimana faktor yang mempengaruhi kepuasan kerja pegawai salah satunya adalah aspek pengawasan yang dapat diidentikkan dengan faktor disiplin kerja. Ini berarti bahwa peningkatan disiplin kerja akan diikuti peningkatan kepuasan kerja yang mereka rasakan (Muntazeri et al., 2018). Sehingga sikap disiplin harus ditanamkan dan dibudayakan oleh setiap pengawas agar dapat mendukung tercapainya tujuan organisasi. Pengawas yang disiplin akan selalu mentaati peraturan yang ditetapkan. Adanya disiplin yang baik mencerminkan seseorang mempunyai tanggung jawab atas pekerjaannya. Saran untuk responden agar lebih meningkatkan disiplin dalam bekerja yaitu dengan lebih bertanggung jawab terhadap tugas dan tanggungjawab yang diberikan dan menaati semua peraturan yang ada di kantor dinas Pendidikan Provinsi Sulawesi Selatan.

\section{Pengaruh Disiplin Kerja Terhadap Kinerja Pengawas}

Terpenuhinya kebutuhan pengawas maka kepuasan kerja yang dirasakan juga semakin tinggi, hal tersebut akan berdampak terhadap kinerjanya. Penting bagi dinas Pendidikan Provinsi Sulawesi Selatan untuk memperhatikan kebutuhan-kebutuhan pengawas seperti memberikan jaminan perlindungan keamanan, memberi penghargaan serta kesempatan kerja untuk mengembangkan potensi dirinya, memberi kesempatan untuk berinteraksi dan mengikutsertakan pengawas untuk mengambil keputusan

Temuan ini sejalan dengan hasil penelitian yang dilakukan oleh (Muntazeri et al., 2018), (Yuliandi \& Tahir, 2019) dan (Anggun Tri Indriastuti, 2014), yang menunjukkan bahwa 
kepuasan kerja mempengaruhi kinerja pegawai. Maka dapat disimpulkan bahwa kepuasan kerja memiliki pengaruh terhadap kinerja pengawas, semakin tinggi peningkatan disiplin maka dapat meningkatkan kinerja pengawas. Sebaliknya, jika tingkat disiplin kerja berkurang, hal ini dapat mengurangi kinerja pengawas. Ini berarti bahwa peningkatan disiplin kerja akan diikuti dengan peningkatan kepuasan yang dirasakan oleh pegawai dalam melaksanakana tugas dan tanggungjawab yang diberikan (Yuliandi \& Tahir, 2019).

Disiplin kerja memiliki peranan tinggi dalam meningkatkan kinerja pengawas. Dengan disiplin kerja yang baik merupakan cerminan besarnya rasa tanggung jawab seseorang pengawas terhadap tugas-tugas yang diberikan kepadanya dengan segala peraturan yang disusun oleh organisasi. Pengawas yang berperilaku disiplin biasanya akan berhasil dalam pekerjaan karena mereka mampu mengatur apa yang menjadi prioritasnya sehingga kinerjanya juga akan baik

Bagi Dinas Pendidikan Provinsi Sulawesi Selatan dalam menegakkan disiplin kerja itu sangatlah penting sekali. Karena dengan adanya disiplin kerja yang baik akan menciptakan kinerja yang baik (Hasibuan, 2002). Seorang pengawas dikatakan akan mempunyai disiplin kerja yang tinggi jika yang bersangkutan konsekuen, konsisten, taat asas, bertanggung jawab atas tugas yang diamanahkan kepadanya. Dengan disiplin kerja yang tinggi akan dapat membantu meningkatkan kinerja pengawas pada dinas Pendidikan Provinsi Sulawesi Selatan.

\section{Pengaruh Kepuasan Kerja Terhadap Kinerja Pengawas}

Dari hasil analisis diketahui bahwa Kepuasan kerja ditemukan berpengaruh secara positif dan signifikan terhadap kinerja pengawas. Semakin tinggi kepuasan kerja pengawas, semakin tinggi kinerja pengawas, kinerja pengawas ditemukan berhubungan positif dengan kepuasan kerja secara keseluruhan (segi kepuasan meliputi kepuasan dengan pekerjaan itu sendiri, supervisi, hubungan dalam kerja, pembayaran, kesempatan promosi, dan kondisi kerja). Kepuasan kerja mempengaruhi kinerja yang dihasilkan karena kepuasan kerja yang mereka miliki.

Seseorang memiliki kepuasan yang tinggi akan memandang pekerjaanya sebagai hal yang menyenangkan, berbeda dengan pegawai yang memiliki kepuasan kerja rendah, ia akan melihat pekerjaannya sebagai hal yang menjemukan dan membosankan sehingga pegawai tersebut bekerja dalam keadaan terpaksa. Seseorang yang bekerja dalam keadaan terpaksa akan memiliki hasil kerja yang buruk dibandingkan dengan pegawai yang bekerja dengan semangat tinggi. Temuan penelitian ini sejalan dengan hasil penelitian (Sudiardhita et al., 2018) yang menyimpulkan bahwa kepuasan kerja memiliki pengaruh positif dan signifikan terhadap kinerja karyawan. Ini berarti bahwa jika kepuasan kerja pegawai meningkat maka kinerja pegawai akan lebih baik. Hal serupa di simpulkan oleh (Barasa et al., 2018) menyimpulkan bahwa kepuasan kerja merupakan faktor dominan yang dapat mempengaruhi kinerja pegawai, variabel kepuasan kerja juga berfungsi sebagai mediasi penuh untuk meningkatkan kinerja pegawai dalam rangka untuk meningkatkan kinerja pengawas.

Organisasi harus memperhatikan aspek kepuasan kerja karena adanya pengaruh yang signifikan terhadap kinerja pengawas. Peningkatan kepuasan kerja dapat dilakukan dengan peningkatan dari segi penghargaan (finansial dan non finansial) yang sepadan dengan beban dan tanggung jawab pekerjaan dan dengan memperhatikan kondisi maupun sarana prasarana yang digunakan sebagai penunjang dalam melaksanakan pekerjaan sebagai pengawas di dinas Pendidikan.

\section{Pengaruh Disiplin Kerja Terhadap Kinerja Pengawas Melalui Kepuasan Kerja}

Hasil penelitian menunjukkan bahwa disiplin kerja secara tidak langsung berpengaruh positif dan signifikan terhadap kinerja pengawas melalui kepuasan kerja. yang dapat dilihat dari nilai T-statistik sebesar 2,345 >1,96. Berdasarkan hasil tersebut dapat disimpulkan bahwa 
disiplin kerja secara tidak langsung berpengaruh positif dan signifikan terhadap kinerja pengawas melalui kepuasan kerja, yang dapat disimpulkan bahwa kepuasan kerja sebagai variabel mediasi. Artinya kinerja seorang pengawas yang didukung oleh sikap disiplin itu merupakan salah satu bagian fungsi operasional manajemen sumber daya manusia (MSDM) yang cukup penting. Hal tersebut mengingat karena sikap disiplin pada pengawas yang semakin membaik, dengan demikian para pegawai akan semakin patuh serta taat pada peraturan-peraturan pada Dinas Pendidikan Proviinsi Sulawesi Selatan.

Selain daripada itu, seorang pengawas harus bertanggung jawab lebih maksimal pada pekerjaannya serta sebaliknya, jika sikap disiplin pengawas itu buruk, maka sikap bertanggung jawab pengawas pada masing-masing pekerjaannya juga akan semakin berkurang, temuan ini sejalan dengan hasil penelitian yang dilakukan oleh (Yuliandi \& Tahir, 2019) yang menyimpulkan bahwa disiplin kerja secara langsung dan tidak langsung (melalui kepuasan kerja) mempengaruhi kinerja karyawan. Oleh karena itu penting untuk menjadi perhatian terhadap peningkatan kesadaran dan sikap sukarela seseorang dalam menaati sebuah peraturan dan sadar terhadap tugas serta tanggung jawabnya, dimana setiap pengawas harus memiliki sikap dan juga perilaku yang taat kepatuhan serta norma-norma yang berlaku pada Dinas Pendidikan Provinsi Sulawesi Selatan.

\section{Pengaruh Pengalaman Kerja Terhadap Kinerja Melalui Kepuasan Kerja}

Pengujian hipotesis menunjukkan bahwa pengaruh tidak langsung pengalaman kerja terhdap kinerja pengawas melalaui kepuasan kerja berpengaruh positif dan signifikan dengan demikian variable kepuasan kerja sebagai variable modiasi. Ini berarti bahwa seorang pengawas yang memiliki pengalaman kerja yang baik akan bekerja dengan baik hal ini karena dipengaruhi faktor lama waktu/masa kerja seseorang, tingkat pengetahuan atau keterampilan yang telah dimiliki dan tingkat penguasaan terjadap pekerjaan dan peralatan. Oleh karena itu seorang pengawas yang mempunyai pengalaman kerja adalah seseorang yang mempunyai kemampuan pengetahuan, dan keterampilan untuk bekerja, karena mereka sudah memiliki rasa puas dalam bekerja. Temuan penelitian ini sejalan dengan hasil temuan penelitian yang dilakukan oleh (Gesinde \& Adejumo, 2012) yang menyimpulkan bahwa pengalaman kerja memiliki hubungan positif yang signifikan terhadap kepuasan kerja dan kinerja.

Hasil penelitian ini memberikan gambaran bahwa pengalaman kerja sangat berperan dalam meningkatkan kinerja pengawas secara tidak langsung atau melalui kepuasan kerja. Pengawas akan lebih mudah dan cepat dalam melaksanakan pekerjaan atau tugasnya, karena mempunyai pengalaman yang lebih dalam pekerjaannya. Sehingga ini akan meningkatkan kinerjanya dan juga meningkatkan kinerja institusi. Adanya pengaruh pengalaman kerja terhadap kinerja pengawas melalui kepuasan kerja di dukung oleh hasil penelitian sebelumnya. Secara empirik menunjukkan bahwa adanya kecenderungan makin lama bekerja, tentu akan memberikan banyak pengalaman kerja yang dimiliki oleh pengawas yang ada dan kecenderungan yang bersangkutan memiliki keahlian dan keterampilan kerja yang relatif tinggi. Sebaliknya keterbatasan pengalaman kerja maka semakin rendah keahlian dan keterampilan kerja yang bersangkutan.

\section{Pengaruh Pengalaman Kerja Terhadap Kepuasan Kerja Pengawas}

Berdasarkan dari hasil analisis data diketahui bahwa pengalaman kerja berpengaruh positif dan signifikan terhadap kepuasan pengawas pengawas, dengan nilai T-Statistics sebesar 9,806 > 1,96. Artinya pengalaman kerja yang dimiliki pengawas seperti tingkat penguasaan pekerjaan, pengetahuan serta keterampilan dalam pekerjaannya mampu membantu dalam menyelesaikan tugas yang diberikan dan tanggungjawab lainnya dengan baik. Adanya pengalaman ini akan memberikan pengetahuan lebih bagi pengawas sehingga pekerjaan akan lebih cepat terselesaikan 
dengan lancar dan tepat waktu yang mampu memberikan kepuasan kerja pegawai. Hasil penelitian ini ditunjang oleh penelitian yang dilakukan oleh (Gesinde \& Adejumo, 2012) yang menyimpulkan bahwa terdapat indikator yang memiliki kontribusi dalam menciptakan kepuasan kerja yang dilatar belakangi oleh pengalaman kerja pegawai seperti keterampilan dan kemampuan tehnik, untuk menilai kemampuan dalam pelaksanaan aspek -aspek tehnik pekerjaan dan latar belakang pribadi, mencakup pendidikan, kursus, latihan, bekerja. Ini nampak dalam sikap positif pengawas terhadap pekerjaan dan segala sesuatu yang dihadapi di lingkungan kerjanya saat ini. dengan demikian semakin banyak pengalaman kerja, maka tingkat kepuasan kerja akan semakin tinggi.

\section{Pengaruh Pengalaman Kerja Terhadap Kinerja Pengawas}

Berdasarkan hasil analisis statistik diperoleh nilai signifikansi T-statistik paling besar yaitu $16.646<1,96.0,000$, dapat disimpulkan bahwa pengalaman kerja secara langsung berpengaruh signifikan terhadap kinerja pengawas. Hal ini mengindikasikan bahwa pengawas yang ada pada dinas Pendidikan Sulawesi Selatan memiliki pemahaman tentang kemampuan kerja, pengalaman kerja yang baik dalam pelaksanaan tugas sehingga akan membantu para pengawas untuk mencapai kinerja yang maksimal. Jadi, ketika kemampuan kerjanya ditingkatkan yang didukung dengan pengalaman kerja yang tinggi maka para pengawas akan mampu memberikan kinerja yang tinggi.

Pengalaman kerja juga berkaitan dengan penguasaan terhadap suatu pekerjaan (Handoko, 2001). Bahwa semakin lama pegawai ditempatkan pada suatu pekerjaan yang sama maka akan semakin menguasainya pekerjaan yang dijalankan. Namun hal ini tergantung dari bagaimana pegawai tersebut memahami dengan benar apa yang menjadi tugasnya. Meskipun pegawai bekerja lama di tempatnya namun tidak memahami apa yang menjadi tugasnya akan menjadi siasia. Penguasaan terhadap pekerjaan dapat dilihat dari penguasaan pegawai terhadap seluruh aspek pekerjaan yang menjadi tanggungjawabnya, apapun pekerjaan yang dihadapinya dapat

dijalankan dengan baik. Temuan dalam penelitian ini bahwa pengawas pada dinas Pendidikan Sulawesi Selatan, sudah menguasai pekerjaannya dan tidak akan mengalami kesulitan dalam menjalankan pekerjaan dan apabila menghadapi kesulitan akan dapat segera menemukan jalan keluarnya, temuan penelitian ini didukung oleh hasil penelitian (Gesinde \& Adejumo, 2012) yang menyimpulkan bahwa pengalaman kerja dapat meningkatkan kinerja pegawai.

\section{SIMPULAN}

Disiplin kerja pengawas pada dinas Pendidikan Provinsi Sulawesi Selatan berdasarkan indikator ketaatan terhadap jam kerja, ketaatan terhadap peraturan, dan bekerja sesuai prosedur termasuk dalam klasifikasi cukup. Artinya, disiplin kerja pengawas belum optimal. Hal ini terlihat masih kurangnya tingkat kehadiran yang belum tepat waktu, masih belum maksimal dalam bertanggung jawab terhadap tugas dan tanggungjawab yang diberikan dan tingkat ketaatan terhadap peraturan yang masih rendah. Artinya pengawas belum memiliki tingkat kepuasan kerja yang baik.

Disiplin kerja pengawas sangatlah penting. Karena dengan adanya disiplin kerja akan terjamin dengan terpeliharanya sebuah tata tertib dan juga kelancaran pelaksana kerja yang akan menciptakan kinerja baik bagi seorang pengawas dinas Pendidikan Provinsi Sulawesi Selatan.

Pengalaman kerja bagi pengawas dinas Pendidikan Provinsi Sulawesi Selatan berdasarkan indikator tingkat pengetahuan yang dimiliki, tingkat keterampilan yang dimiliki, dan penguasaan terhadap pekerjaan dan peralatan termasuk dalam kriteria baik dengan kinerja baik. Artinya, secara keseluruhan pengawas sudah berpengalaman dan mampu menciptakan tingkat kepuasan kerja sorang pengawas dengan baik. 
Kinerja pengawas dinas Pendidikan Provinsi Sulawesi Selatan berdasarkan indikator kualitas, kuantitas, dan ketepatan waktu termasuk kedalam kriteria belum baik. Artinya, kinerja pengawas pada Disdik Provinsi Sulawesi Selatan belum optimal. Hal ini terlihat dari adanya pengaruh pengalaman kerja yang dimiliki oleh masing-masing pengawas yang berbeda-beda.

Kepuasan kerja pengawas yang baik akan menciptakan kinerja yang baik pula, hal ini tercermin pada seorang pengawas yang memiliki kepuasan yang tinggi akan memandang pekerjaanya sebagai hal yang menyenangkan.

Secara tidak langsung disiplin kerja melalui kepuasan kerja berpengaruh terhadap kinerja pengawas dinas Pendidikan Provinsi Sulawesi Selatan, dengan kontribusi tingkat kedisiplinan yang cukup baik memberikan dampak terhadap peningkatan kinerja pengawas.

Secara tidak langsung pengalaman kerja melalui kepuasan kerja berpengaruh terhadap kinerja pengawas dinas Pendidikan Provinsi Sulawesi Selatan, dengan kontribusi pengalaman kerja berpengaruh tinggi. Sehingga dapat disimpulkan bahwa Disdik Provinsi Sulawesi Selatan lebih efektif meningkatkan kinerja pengawas melalui kepuasan kerja.

\section{REFERENSI}

Agussalim, M. (2017). Analysis Work Discipline and Work Spirit to Achievement Employees Pt Japfa. Saudi Journal of Business and Management Studies, 2(3B), 286-296. https://doi.org/10.21276/sjbms.2017.2.3.22

Anggun Tri Indriastuti. (2014). Pengaruh Budaya Organisasi Dan Lingkungan Kerja Terhadap Kepuasan Kerja Dan Kinerja Karyawan Pada PT. Bank Muamalat Indonesia Divisi Konsumer Area Cabang Surabaya. JMM17 Jurnal Ilmu Ekonomi \& Manajemen, 1(1), 8393.

Barasa, L., Gunawan, A., \& Bambang Sumali. (2018). Determinants of Job Satisfaction and it's Implication on Employee Performance of Port Enterprises in DKI Jakarta. International Review of Management and Marketing, 8(5), 43-49.

Gesinde, A. . M., \& Adejumo, G. . O. (2012). Effects of Age and Work Experience on Job Satisfaction of Primary School Teachers: Implications for Career Counseling. Asian Economic and Social Society Effects, 7(June), 1-25.

Ghazali, I., \& Latan, H. (2012). Partial Least Square: Konsep, Teknik dan Aplikasi Menggunakan SmartPLS.

Handoko, T. H. (2001). Manajemen Personalia dan Sumber Daya Manusia (Kedua). BPFE.

Hasibuan, M. S. P. (2002). Manajemen Sumber Daya Manusia (Edisi Revisi (ed.)). PT. Bumi Aksara.

Hutagalung, M., \& Triastuti, Y. (2019). Pengaruh Lingkungan, Motivasi Dan Disiplin Terhadap Kinerja Karyawan Pada Pt. Anugerah Abadi Bersama. Jurnal Pengembangan Wiraswasta, 21(2), 123. https://doi.org/10.33370/jpw.v21i2.328

Imam, G. (2011). Aplikasi analisis multivariate dengan program IBM SPSS 19. Semarang: Badan Penerbit Universitas Diponegoro.

Imam Ghozali. (2006). Aplikasi analisis multivariate dengan program SPSS. Badan Penerbit Universitas Diponegoro.

Itafia, Y., Cipta, W., Yudiaatmaja, F., Manajemen, J., \& Ganesha, U. P. (2014). Pengaruh Pengalaman Kerja Dan Kepuasan Kerja Terhadap Produktivitas Kerja Karyawan Pada Industri Tenun. E-Journal Bisma Universitas Pendidikan Ganesha, 2(4).

Luthans, F., Vogelgesang, G. R., \& Lester, P. B. (2006). Developing the psychological capital of resiliency. Human Resource Development Review, 5 (1), 25-44.

Muntazeri, S., Indrayanto, A., \& Kayode, B. K. (2018). The impact of education, training and work experience on job satisfaction and job performance. Jurnal Akuntansi, Manajemen Dan Ekonomi, 20(2), 50-69. 
Nugrohadi, I. A. W., Nurmingsih, \& Pujiwati. (2019). The Effect Of Work Discipline And Organizational Culture On Employee Performance In Type D General Hospitals In Dki Jakarta (Study at Type D General Hospital in East Jakarta). International Respati Health Conference, 865-877.

Robbins, S. P., \& Judge, T. A. (2006). Perilaku Organisasi (Edisi Kese). PT Indeks Kelompok Gramedia.

Solimun, M. S. (2002). Structural Equation Modelling (SEM) Lisrel dan Amos. Fakultas MIPA Universitas Brawijaya.

Sudiardhita, K. I. R., Mukhtar, S., Hartono, B., Herlitah, Sariwulan, T., \& Nikensari, S. I. (2018). The effect of compensation, motivation of employee and work satisfaction to employee performance PT. Bank XYZ (Persero) Tbk. Academy of Strategic Management Journal, 17(4), 1-14.

Sugiyono. (2017). Metode Penelitian Kuantitatif, Kualitatif, dan R\&D. Alfabeta.

Sutrisno, E. (2009). Manajemen Sumber Daya Manusia (Pertama). Kencana Prenada Media Group.

Yuliandi, \& Tahir, R. (2019). Work discipline, competence, empowerment, job satisfaction, and employee performance. International Journal of Recent Technology and Engineering, 8(3), 7209-7215. https://doi.org/10.35940/ijrte.C6221.098319. 